\title{
Terminalia avicennioides Guill \& Perr (Combretaceae): Pharmacology and Phytochemistry of an Alternative Traditional Medicine in Nigeria: Mini Review
}

\author{
Hadiza Aliyu ${ }^{1 *}$, Mohammed Suleiman ${ }^{1}$, Abubakar Ahmed $^{2}$, Ngozi Chiezey $^{3}$, Aroke Ahmed $^{4}$, Muhammed Mamman $^{1}$ and Lyndy McGaw ${ }^{5}$ \\ ${ }^{1}$ Department of Pharmacology and Toxicology, Faculty of Veterinary Medicine, Ahmadu Bello University, Zaria, Nigeria \\ ${ }^{2}$ Department of Pharmacognosy and Drug Development, Faculty of Pharmaceutical Sciences, Ahmadu Bello University, Zaria, Nigeria \\ ${ }^{3}$ Department of Parasitology and Entomology, Faculty of Veterinary Medicine, Ahmadu Bello University, Zaria, Nigeria \\ ${ }^{4}$ Federal Institute of Industrial Research, Oshodi, Lagos State, Nigeria \\ ${ }^{5}$ Department of Paraclinical Studies, Faculty of Veterinary Sciences, Phytomedicine Program, University of Pretoria, Pretoria, South Africa
}

*Corresponding author: Hadiza Aliyu, Department of Pharmacology and Toxicology, Faculty of Veterinary Medicine, Ahmadu Bello University, Zaria, Nigeria, Tel: +2348027149001; E-mail: haliyu63@gmail.com

Received date: March 05, 2018; Accepted date: March 14, 2018; Published date: March 19, 2018

Copyright: (c) 2018 Aliyu H, et al. This is an open-access article distributed under the terms of the Creative Commons Attribution License, which permits unrestricted use, distribution, and reproduction in any medium, provided the original author and source are credited.

\begin{abstract}
This is a literature survey of the genus Terminalia, a member of the family Combretaceae with emphasis on Terminalia avicennioides. T. avicennioides is a plant of medicinal importance common in Africa and Asia. The plant has been reported to be used by traditional medical practitioners to treat a variety of conditions including inflammation, oxidative stress and cytotoxicity in both humans and animals.
\end{abstract}

Keywords: Terminalia avicennioides; Phytochemistry; Antiinflammatory; Antioxidant; Cytotoxicity

\section{Introduction}

Traditional medical practices worldwide have employed herbal remedies for the prevention and treatment of different diseases. Scientific research and clinical trials have confirmed the efficacy of several plants in the treatment and prevention of a number of conditions [1]. Phytomedicine is the use of any part of a plant including the seeds, berries, roots, leaves, bark, or flowers for medicinal purposes, the leaves and tree are shown in Figures 1 and 2 respectively. In many developing countries, herbal medicinal systems remain important in the treatment of many ailments. Ayurvedic medicine is still commonly practiced within India with an estimated $85 \%$ of Indians still using crude plant preparations [2]. Traditional Chinese medicine (TCM) and African medicinal systems also account for a major portion of health care in their populations. Many of the prescription drugs currently in the market were originally isolated from plants and/or are semi-synthetic analogues of phytochemicals (chemical constituents of plants). The trend is to isolate and characterize the individual phytochemical components with the aim of producing an analogue of increased bioactivity or bioavailability. Such studies have given rise to many useful drugs like the anticancer drugs vincristine and vinblastine (from Vinca rosea). [3].

Combretaceae is a large family of trees, shrubs, vines and mangroves [4]. It is found in the tropical and subtropical regions worldwide, with the highest diversity in Asia and Africa [5]. Two of the largest and most useful genera are Combretum, and Terminalia [6]. Terminalia comprises species of medium to large flowering trees, many of which have a history of usage in traditional medicinal systems [7]. Terminalia species are widely distributed throughout the tropical and subtropical regions of Asia, Australia and Africa. Different species occur in different parts of the continent and their usage, which is often widespread, is also associated with specific cultural/ethnic groups. Thus, a species used by one cultural group for a specific property may either have a different therapeutic use or none by other groups in different regions of the continent [8].

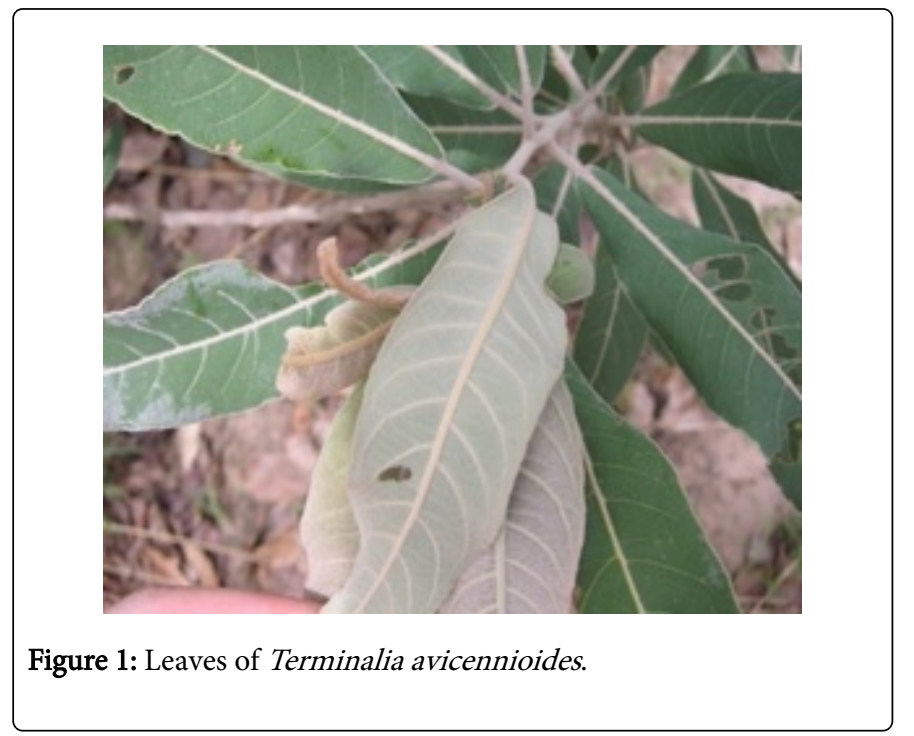

Phytochemical studies performed on different Terminalia species have demonstrated the occurrence of several classes of chemical constituents, such as tannins, pentacyclic triterpenes and their glycoside derivatives, flavonoids and other phenolic compounds [9]. $T$. avicennioides known as Baushe (Hausa, Northern Nigeria), Igi odan (Yoruba, Southwest Nigeria), and Ebo (Igbo, Southeast Nigeria) [10], has been used with apparent success in Nigeria, particularly among the rural population and the rich history and successes of its use is due to 
Citation: $\quad$ Aliyu H, Suleiman M, Ahmed A, Chiezey N, Ahmed A, et al. (2018) Terminalia avicennioides Guill \& Perr (Combretaceae): Pharmacology and Phytochemistry of an Alternative Traditional Medicine in Nigeria: Mini Review. J Pharmacogn Nat Prod 4: 152.

Page 2 of 4

the fact that modern medicines are expensive and beyond the reach of the majority of the populace [1].

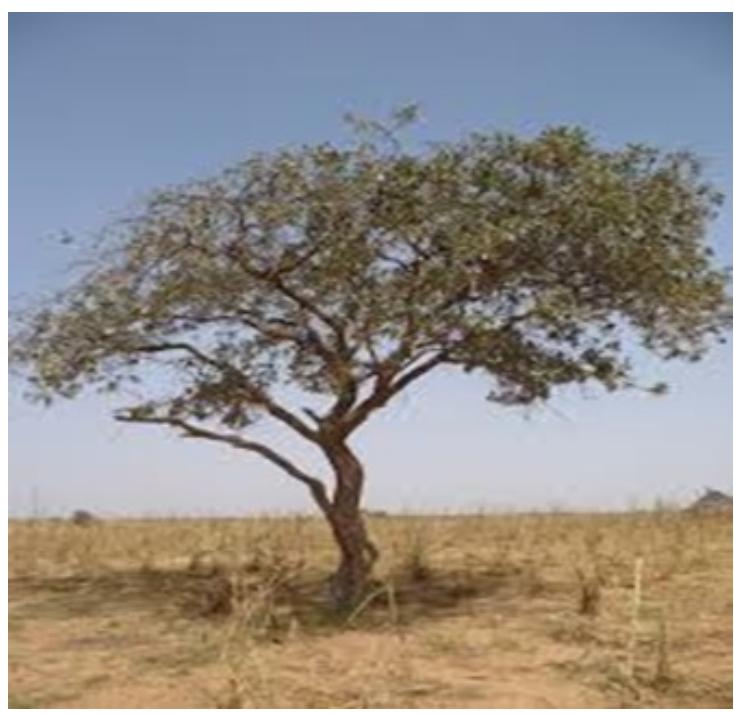

Figure 2: Terminalia avicennioides tree.
Preparations from various parts of the plant have been ethnopharmacologically validated using modern pharmacological research techniques to determine their biological activities (Table 1).

\begin{tabular}{|c|c|c|c|c|}
\hline $\begin{array}{l}\text { Biological activities of } T . \\
\text { avicennioides }\end{array}$ & $\begin{array}{l}\text { Type of } \\
\text { studies }\end{array}$ & Results & Observations/Comments & References \\
\hline Antioxidant & In vivo & $\begin{array}{l}\text { Increased liver superoxide dismutase } \\
\text { (SOD) and catalase with decreased } \\
\text { Malondialdehyde (MDA) }\end{array}$ & $\begin{array}{l}\text { Terminalia avicennioides has antioxidant } \\
\text { properties and can boost antioxidant level in } \\
\text { organisms }\end{array}$ & {$[11,12]$} \\
\hline Enzymatic inhibition & In vivo & $\begin{array}{l}\text { Extract from the plant prevented the } \\
\text { (diethylnitrosamine) DEN-induced } \\
\text { increase in the liver enzymes ALT, } \\
\text { AST, ALP and GGT }\end{array}$ & The extract possess hepatoprotective activity & {$[13]$} \\
\hline Anticancer & In vitro & $\begin{array}{l}\text { Decrease in cancer cell viability assay } \\
\text { which is dose- and time-dependent }\end{array}$ & $\begin{array}{l}\text { Extract of the plant is cytotoxic against the } \\
\text { (Ehrlich ascites carcinoma) EAC cell lines }\end{array}$ & {$[10,14]$} \\
\hline Anticonvulsant & In vivo & $\begin{array}{l}\text { Pentylenetetrazole-induced } \\
\text { convulsion was reduced in a dose- } \\
\text { dependent pattern }\end{array}$ & $\begin{array}{l}\text { Ability of the extract to protect rats stimulated } \\
\text { with pentylenetetrazole may be an indication } \\
\text { of its pharmacological depressant activity on } \\
\text { both the spinal cord and the brain stem }\end{array}$ & {$[15]$} \\
\hline
\end{tabular}

Table 1: Some Pharmacologic activities of different parts of Terminalia avicennioides.

\section{Phytochemicals}

Phytochemicals are naturally occurring constituents of plants, they are found in different parts of a plant including the bark, leaves, flowers, roots, fruits and seeds. These are metabolites synthesized by plants as part of their defense mechanisms; alkaloids, glycosides, resins, volatile oils, gums, tannins, flavonoids, terpenes and phenols with the active principles usually found concentrated in the storage organs of the plants. Information on the chemical constituents of plants is necessary as these will be useful in the synthesis of complex chemical compounds. The aqueous root bark extracts of $T$. avicennioides has been reported to contain flavonoids, tannins, phenols, saponins, alkaloids and other phytochemicals [16], they have also been reported to exhibit free-radical scavenging, anti-oxidant and anticancer activities [13].

\section{Antioxidant activity}

The high antioxidant contents of many Terminalia species have been of significant importance. Consumption of high levels of antioxidants (as are characteristic of Terminalia species) may prevent the formation of tumor [8,17], and prevent some other conditions such as neural degeneration [18]. Phenolic compounds have been known to possess a strong antioxidant activity [19] with the primary function of protecting cell constituents against oxidative damage by scavenging the free radicals, thereby preventing their detrimental effects on nucleic acids, proteins, and lipids in the cells [19]. The high antioxidant activities of plants of the genus Terminalia can be associated with their phenolic contents [20]. Common plant phenolic compounds include flavonoids, tannins, anthocyanins, and Gallic acid, all of which are common phytochemical constituents of Terminalia species. The high tannin and flavonoid contents associated with this genus; have been implicated for 
Citation: Aliyu H, Suleiman M, Ahmed A, Chiezey N, Ahmed A, et al. (2018) Terminalia avicennioides Guill \& Perr (Combretaceae): Pharmacology and Phytochemistry of an Alternative Traditional Medicine in Nigeria: Mini Review. J Pharmacogn Nat Prod 4: 152.

doi: 10.4172/2472-0992.1000152

Page 3 of 4

the antioxidant activity [21]. The tannin content of the Asian species $T$. chebula has been reported to be as high as 32\% [22]. The antioxidant activity of $T$. arjuna bark studied was observed to be comparable to the standard antioxidant ascorbic acid in its free radical scavenging and lipid peroxidation activities [23]. Also, The antioxidant activities of the methanolic fruit extract of $T$. bellerica studied by in vitro assay using 2,2-diphenyl-1-picrylhydrazyl (DPPH), oxygen radical absorbance capacity (ORAC) and ferric reducing ability of plasma (FRAP) exhibited a high antioxidant activity; the high antioxidant activity of the aqueous methanolic extracts of the leaves, bark and fruits of $T$. arjuna, T. bellerica, T. chebula and T. muelleri were attributed to their high phenolic contents [24]. Similarly, the high antioxidant contents have also been reported for the African species including $T$. brachystemma, T. gazensis, T. mollis, T. pruniodes, T. sambesiaca and T. sericea [25], the aqueous root bark extracts of T. avicennioides has been observed to possess antioxidant activity exhibited by the hepatoprotective and haemoprotective activities against hepatic oxidation-reduction reaction (redox) and haemostatic imbalances caused by diethylnitrosamine (DEN) in rats, which measured up well with that of curcumin [26].

\section{Anti-inflammatory activity}

Inflammation is a complex response by the body to injury; it typically follows a variety of insults including burns, wounds, bites, stings, etc. It is characterized by a wide range of symptoms including swelling, redness and pain [27]. The inflammatory processes require the cellular release of several classes of molecules; vasoactive substances (such as bradykinin, prostaglandins, and vasoactive amines) to dilate blood vessels and open junctions located between cells to allow leucocytes to pass through the capillaries. Any compound capable of blocking these vasoactive substances would potentially have a therapeutic effect as an anti-inflammatory agent [28]. There are no known scientific studies to buttress the anti-inflammatory property of T. avicennioides as claimed by traditional medical practitioners. However, potent anti-inflammatory activity has been reported with some other species such as, T. sericea [29]. But, from the phytochemical analysis of $T$. avicennioides, flavonoids and tannins which have anti-inflammatory activities are also present in the plant this suggests that the plant too can be said to have an antiinflammatory activity as claimed by the local people.

\section{Cytotoxicity}

Cancer is responsible for the high rates of human mortality, and for decades, research has been conducted on plants in order to identify new agents that have activity against cancerous growths. The growth and development of healthy cells depend on adequate regulation of growth promoting and inhibiting pathways. In tumor formation, multiple genes may be altered and transmitted to daughter cells, which subsequently escape normal growth restraints and form a tumor that may be benign or malignant. Induction of oxidative stress has also been linked to several types of cancer [30]. Thus, it is possible that the high antioxidant contents of many Terminalia species may inhibit cancer formation and/or progression [8]. Chromosome instability is also a common feature of many of the cancers that have been linked to oxidative stress, suggesting that increased oxidative stress may contribute to the development of genetic instability resulting in the emergence of new tumor phenotypes [8]. The focus on the pharmacologic effects of bioactive compounds on cancer treatments and prevention has increased with the use of 3-(4,5- dimethylthiazol-2- y1)-2,5-diphenyl tetrazolium bromide (MTT) assay [31]. T. avicennioides roots, was tested on different cell lines and was shown to reduce the proliferation of breast cancer cells MCF-7 $\left(\mathrm{IC}_{50}=78 \mathrm{mM}\right)$ and inhibited the proliferation of murine sarcoma S180 cancer cells $\left(\mathrm{IC}_{50}\right.$ value $\left.7.4 \mathrm{mM}\right)$ [32-35].

\section{Future outlook}

With the presence of the plant in Nigeria, further study and investigation of its antimicrobial activities, its safety and the isolation of its active constituents may still be carried out to prove its potential biological properties and medicinal values.

\section{Conclusion}

T. avicennioides is an important plant with great medicinal value; investigations carried out on the plant have shown it to have activities either palliative or curative against a variety of conditions including, inflammatory and oxidative stress which can result into tumor formation and neurodegeneration. It is therefore imperative that more investigation should be carried out especially on its safety so as to know the effective and safe dose for consumption.

\section{References}

1. Suleiman M, Romanus I, Yusuf S (2007) Gastroprotective effect of crud methanol extract of Terminalia avcennoides in rats. Veterinarski Arch 77: 345-354.

2. Kamboj V (2000) Herbal medicine. Cur Sci 78:35-39.

3. Choi S, Chung M (2003) A review on the relationship between Aloe vera components and their biological effects. Seminar Integrated Medicine 1: 53-62.

4. Maurin O, Chase M, Jordaan M, Van Der Bank M (2010) Phylogenetic relationships of Combretaceae inferred from nuclear and plastid DNA sequence data: Implications for generic classification. Botany J Linn Soc 162: 453-476.

5. Mabberley D (2008) The plant-book: A portable dictionary of the vascular plants. $3^{\text {rd }}$ edn Cambridge: Cambridge University Press.

6. Cock I, Van Vuuren S (2015) A comparison of the antimicrobial activity and toxicity of six Combretum and two Terminalia species from Southern Africa. Pharmacog Mag 11: 208-218.

7. McGaw L, Rabe T, Sparg S, Jager A, Ejoff J, et al. (2001) An investigation on the biological activity of Combretum species. J Ethnopharmacol 75: 45-50.

8. Cock I (2015) Medicinal properties and phytochemistry of plants of the genus Terminalia (Combretaceae). Inflammopharmacology 23: 203.

9. Garcez F, Garcez W, Miguel D, Serea A, Prado F, et al. (2003) Chemical constituents from Terminalia glabrescens. J Bra Chem Soc 14: 461- 465.

10. Mann A, Ajiboso O, Ajeigbe S, Gbate M, Isaiah S, et al. (2011) Evaluation of the wound healing activity of ethanol extract of Terminalia avicennioides root bark on two wound models in rats. Inter J Med Aromatic Plants 1: 95-100.

11. Omonkhua A, Cyril-Olutayo M, Akanbi O, Adebayo O (2013) Antimalarial, hematological, and antioxidant effects of methanolic extract of Terminalia avicennioides in Plasmodium berghei-infected mice. Parasitol Res 112: 3497-3503.

12. Akanbi O (2013) In vivo Study of Antiplasmodial Activity of Terminalia avicennioides and Its Effect on Lipid Profile and Oxidative Stress in Mice Infected with Plasmodium berghei. British Microbiol Res J 3: 501-512.

13. Salau A, Yakubu M, Oladiji A (2015) In vitro and in vivo antioxidant activity of aqueous extracts of Anogeissus leiocarpus (DC) Guill \& Perr and Terminalia avicennioides Guill \& Perr root barks. Cam J Biol Biochem Sci 23: 9-16. 
Citation: Aliyu H, Suleiman M, Ahmed A, Chiezey N, Ahmed A, et al. (2018) Terminalia avicennioides Guill \& Perr (Combretaceae): Pharmacology and Phytochemistry of an Alternative Traditional Medicine in Nigeria: Mini Review. J Pharmacogn Nat Prod 4: 152.

Page 4 of 4

14. Sanon S, Gansane A, Ouattara L, Traore A, Ouedraogo I, et al. (2013) In vitro antiplasmodial and cytotoxic properties of some medicinal plants from Western BurkinaFaso. Afri J Lab Med 81: 1-7.

15. Idris M, Abdulrahman F, Tijjani M, Sandabe U (2014) Effects of ethanol leaf extract of Terminalia avicennoides Guill \& Perr on the central and peripheral nervous system. Int J Phytopharm Res 5: 178-183.

16. Salau A, Yakubu M, Oladiji A (2013) Cytotoxic activity of aqueous extracts of Anogeissus leiocarpus and Terminalia avicennioides root barks against Ehrlich ascites carcinoma cells. Ind J Pharmacol 45: 381-385.

17. Hertog M, Bueno-de-Mesquita H, Fehily A, Sweetnam P, Elwood P, et al. (1996) Fruit and vegetable consumption and cancer mortality in the caerphilly study. Cancer Epidemiol Biomark Prevention 5: 673-677.

18. Youdim K, Spencer J, Schroeter H, Rice-Evans C (2002) Dietary flavonoids as potential neuroprotectans. Bioll Chem 383: 503-519.

19. Rice-Evans C, Miller N (1997) Paganga. Antioxidant properties of phenolic compound. Trends Plant Sci 2: 152-159.

20. Jaiwal B, Shaikh F, Waghire H, Sarwade B. (2012) Comparative antioxidative potential of barks of phenolic extract of genus Terminalia. Inter J Sci Pharmacol Edu Res 1: 6-10.

21. Chang C, Lin C (2012) Phytochemical composition, antioxidant activity, and neuroprotective effect of Terminalia chebula Retzius extracts. Evid Based Complementary and Alternative Medicine. Article ID 125247.

22. Chattopadhyay R, Battacharyya S (2007) Plant review: Terminalia chebula: an update. Pharmacognosy Review 1: 151-156.

23. Viswanatha G, Vaidya S, Krishnadas N, Rangappa S (2010) Antioxidant and antimutagenic activities of bark extract of Terminalia arjuna. Asian Pac J Tropl Biomed 3: 965-970.

24. Bajpai M, Pande A, Tewari S, Prakash D (2005) Phenolic contents and antioxidanactivity of some food and medicinal plants. Inter J Food Sci Nutri 56: 287-291.
25. Masoka P, Eloff J (2005) The diversity of antifungal compounds of six South African Terminalia species (Combretaceae) determined by bioautography. Afri J Biotech 4: 1425-1431.

26. Salau A, Yakubu M, Oladiji A (2016) Effects of aqueous root bark extracts of Anogeissus leiocarpus (DC) Guill \& Perr and Terminalia avicennioides Guill \& Perr on redox and haematological parameters of diethylnitrosamine-administered rats. Iranian J Toxicology 10: 21-29.

27. Macpherson G (1992) Inflammation. Blacks Medical Dictionary; A and C Black, London, UK.

28. Anjaneyulu A, Prasad A (1982) Chemical examination of roots of Terminalia arjuna (Roxb.) Wight \& Arnot. Part I. Characterisation of two new triterpenoid glycosides. Indian Journal of Chemistry 21: 530-533.

29. Moshi M, Mbwambo Z (2005) Some pharmacological properties of extracts of Terminalia sericea roots. J Ethnopharmacol 97: 43-47.

30. Tome M, Baker A, Powis G, Payne C, Briehl M, et al. (2001) Catalase overexpressing thymocytes are resistant to glucocorticoid-induced apoptosis and exhibit increased net tumour growth. Cancer Res 61: 2766-2773.

31. Mosmann T (1983) Rapid colorimetric assay for cellular growth and survival: application to proliferation and cytotoxicity tests. J Immunological Meths 65: 55-63.

32. Anjaneyulu A, Prasad A (1982) Chemical examination of roots of Terminalia arjuna - the structure of arjunoside III and arjunoside IV, two new triterpenoid glycosides. Phytochemistry 21: 2057-2060.

33. Cragg G, Newman D (2005) Biodiversity: A continuing source of novel drug leads. J Pure Appl Chem 77: 7-24.

34. Parveen U, Roy S, Kumar A (2007) Traditional uses of medicinal plants among the rural communities of Churu district in the Thar Desert, India. J Ethnopharmacol 113: 387-99.

35. World Health Organization (WHO): The promotion and development of traditional medicine. Tech report series, 1978: 622. 